\title{
Correction to: The Vegetable Seed Market in Russia: Incentive Proposals for Greater Development
}

\author{
Vasiliy I. Nechaev (D), Pavel V. Mikhaylushkin $(\mathbb{D}$, \\ and Sergey A. Arzhantsev (D)
}

\section{Correction to:}

Chapter "The Vegetable Seed Market in Russia: Incentive Proposals for Greater Development" in: A. V. Bogoviz (ed.), The Challenge of Sustainability in Agricultural Systems, Lecture Notes in Networks and Systems 205, https://doi.org/10.1007/978-3-030-73097-0_43

In the original version of the book, the following belated correction has been incorporated:

In the chapter "The Vegetable Seed Market in Russia: Incentive Proposals for Greater Development", the affiliation of Pavel V. Mikhaylushkin has been changed from "Federal Research Center of Agrarian Economy and Social Development of Rural Areas - All Russian Research Institute of Agricultural Economics, Moscow, Russia" to "Federal Research Center of Agrarian Economy and Social Development of Rural Areas - All Russian Research Institute of Agricultural Economics, Moscow, Russia; Kuban State Agrarian University, Krasnodar, Russia”.

The book and the chapter have been update with the change. 